\title{
Nationwide Survey on Family-perceived Experiences of Patients With Cancer of Unknown Primary Site
}

\section{Kyoko Ishida ( $\sim$ k_ishida@nagoya-u.jp)}

Nagoya University Graduate School of Medicine, Department of Nursing, Doctoral Course https://orcid.org/0000-0001-6829-8163

Kazuki SATO

Nagoya University, Nursing for Advanced Practice, Department of Integrated Health Sciences

\section{Hirokazu KOMATSU}

Nagoya City University, Department of Hematology and Oncology

Tatsuya MORITA

Seirei Mikatahara Hospital, Department of Palliative and Supportive Care, Palliative Care Team and Seirei Hospice

\section{Tatsuo AKECHI}

Nagoya City University Graduate School of Medical Science, Department of Psychiatry and Cognitive-Behavioral Medicine

Megumi UCHIDA

Nagoya City University Graduate School of Medical Sciences, Department of Psychiatry and Cognitive-Behavioral Medicine

Kento MASUKAWA

Tohoku University Graduate School of Medicine, Department of Palliative Nursing, Health Sciences

\section{Naoko IGARASHI}

Tohoku University Graduate School of Medicine, Department of Palliative Nursing, Health Sciences

\section{Yoshiyuki KIZAWA}

Kobe University Graduate School of Medicine, Department of Palliative Medicine

\section{Satoru TSUNETO}

Kyoto University Graduate School of Medicine, Department of Human Health Sciences

\section{Yasuo SHIMA}

Tsukuba Medical Center Hospital, Department of Palliative Medicine

\section{Mitsunori MIYASHITA}

Tohoku University Graduate School of Medicine, Department of Palliative Nursing, Health Sciences

\section{Shoko ANDO}

Nagoya University Graduate School of Medicine Faculty of Medicine: Nagoya Daigaku Daigakuin Igakukei Kenkyuka Igakubu

\section{Research Article}

Keywords: Unknown Primary Tumors, Family, Experience, Burden, Uncertainty, Early Diagnosis

Posted Date: January 14th, 2022

DOl: https://doi.org/10.21203/rs.3.rs-1174384/v1

License: @ (1) This work is licensed under a Creative Commons Attribution 4.0 International License. Read Full License 


\section{Abstract}

Purpose: Cancer of unknown primary site (CUP) is an aggressive disease with poor prognosis. As research on the experiences of CUP patients and their families is scarce, this study aimed to compare the family-perceived burden of CUP with that of common cancers (lung, colon, and stomach cancer). Additional aims were to explore the association between family-perceived burden and CUP patients' quality of life (QOL) at end-of-life and family depression.

Methods: This was a pre-planned secondary analysis of nationwide cross-sectional survey data from the bereaved family members of patients with cancer who died at 286 institutions. The major measurements were the eight-item family-perceived Burden scale (comprising specialist access, uncertainty, and prolonged diagnosis), Good Death Inventory, and Patient Health Questionnaire 9.

Results: Of the total 27,591 survey responses, we analyzed 97 and 717 responses from the family members of patients with CUP and common cancer, respectively. The families of CUP patients scored significantly higher on all three burden subscales than those of common cancer patients (effect sizes: specialist access subscale, 0.3 ; uncertainty subscale, 0.66 ; and prolonged diagnosis subscale, 0.69 ; adjusted $\mathrm{P}<0.01$ ). Greater family Burden was significantly associated with lower patient $\mathrm{QOL}$ and higher family depression. Burden was significantly associated with being a spouse, second opinion consultation, and diagnosis period of $>1$ month.

Conclusion: The families of CUP patients experience poor specialist access, greater uncertainty, and a prolonged diagnosis. They should be cared for from the initial stages to establish access to specialists, obtain an early diagnosis, and reduce uncertainty.

\section{Introduction}

Cancer of unknown primary site (CUP) is a clinically aggressive disease with early dissemination [1-2], resulting in poor prognosis with a median survival time of 6 months [3]. While research on the medical aspects of CUP has been increasing [4-8], information on the experiences of CUP patients and families is scarce. To date, some qualitative studies demonstrated that CUP patients experience uncertainty and difficulty when accepting the CUP diagnosis $[9,10]$ and that CUP patients experience anxiety, disbelief, and frustration in addition to uncertainty from onset to initial treatment [11]. Quantitative studies are limited, and only one large quantitative study compared experiences between CUP and other cancer patients, which revealed that CUP patients were less likely to have understood the explanations of their condition [12]. Furthermore, CUP patients' families may experience considerable burden [13, 14], but very little research has focused on the family members of CUP patients [10]. Empirical evidence suggests that family caregivers sometimes become more depressed than patients themselves [15] and that they face continued burden after the patient's death [16, 17]. A greater understanding of the experiences of CUP patients' families is valuable for developing an appropriate strategy to care for both CUP patients and their families.

The main purpose of this study was thus to compare the family-perceived burden of CUP patients and those with common cancers (lung, colon, and stomach cancer). The secondary aims were 1) to explore the association between family-perceived burden on family members and the patients' quality of life (QOL) at end-of-life and depression among bereaved family members and 2) to identify factors related to family-perceived burden.

\section{Methods}

This study was conducted as a part of the Japan Hospice and Palliative Care Evaluation (J-HOPE) with the aim to evaluate the quality of palliative care services from the perspective of bereaved families $[18,19]$. This was a cross-sectional nationwide survey using anonymous, self-administered questionnaires. For the present study, data from two surveys, namely J-HOPE 2016 (conducted MayJuly 2016) and J-HOPE 4 (July-September 2018) [18, 19], were combined to achieve the necessary sample size.

\section{Subjects}

Potential subjects were bereaved family members of cancer patients who had died at each participating institution between November 2013 and January 2016 (J-HOPE 2016) and between February 2016 and January 2018 (J-HOPE 4). Participating institutions were certified inpatient hospices/palliative care units (PCUs), home care services, and acute hospitals belonging to the Japan Hospice and Palliative Care Foundation. The eligibility criteria were as follows: adult bereaved family members of a patient that died of cancer, the deceased patient was aged $\geq 20$ years, and the patient was an inpatient in a PCU for $>3$ days. The exclusion criteria were as follows: a PCU stay $<3$ days, inability to identify a family member, treatment-associated death or death in an intensive care unit, suffering serious 
psychological distress, inability to complete the self-report questionnaire because of health issues, and overall judgment of the healthcare professionals.

\section{Procedures}

Questionnaires were sent by mail to identified family members directly by each participating institution, and uninterested participants were asked to check the "No Participation" box and return the incomplete questionnaire. Participants were provided detailed information in the form of an enclosed letter of intent about participation being voluntary, absence of medical disadvantage due to nonparticipation, and assurance of complete anonymity. We asked that the respondents be family members who were the main caregivers of the patient and who had the most knowledge about the treatment provided to the patient. Completed questionnaires were retuned by the participants to the research secretariat, and data management at the secretariat was independent of all participating institutions. Return of a completed questionnaire was defined as consent for study participation. A reminder was sent to non-responders one month after the questionnaire was sent out.

\section{Measurements}

The questionnaire for this study was developed by the authors on the basis of a literature review $[9,10,20,21]$, a previous qualitative study using interviews with 9 CUP patients [11], and extensive discussions among the authors. Content validity was confirmed by a pilot test with three bereaved family members and unanimous agreement among the authors.

\section{Burden on family members associated with cancer testing and diagnosis (family-perceived burden scale: Burden)}

The Burden scale was developed to assess the family's experiences related to cancer testing and diagnosis and comprised eight items. Each item was rated on a four-point Likert scale (1: Not at all, 2: Almost never, 3: Sometimes, and 4: Often). Subscale scores were defined as the mean scores of the included items, and the total score was defined as the mean of the subscale scores: each was scored on a scale of $1-4$, and higher scores indicated greater Burden.

\section{Good death inventory (GDI)}

Patients' QOL at end-of-life was assessed using the short version of the GDI, which measures achievement of a good death from the perspective of bereaved family members. The short GDI consists of 18 representative items from each domain of the original version and its validity and reliability have been previously confirmed [22]. Responses were rated on a scale from 1 to 7 , with a high total score indicating good death [22].

\section{Patient Health Questionnaire 9 (PHQ-9)}

Depression was assessed using PHQ-9; the reliability and validity of the Japanese version have been previously confirmed [23-26]. Each of the nine items explore the extent to which a particular depressive symptom has bothered the respondent in the preceding 2 weeks. Responses are rated on a scale from 0 to 3, with total scores ranging from 0 to 27 [23, 24].

\section{Participant characteristics}

The patients' age, sex, and primary cancer site from their medical records were recorded by the physician responsible for patient treatment at each of the participating institutions. We also asked bereaved family members for their age, sex, relationship to the patient, and educational background as part of the questionnaire.

\section{Background of the diagnosis of CUP patients}

Only the bereaved family members of CUP patients were asked for details regarding patients' chief complaint at the time of the first hospital visit, length of time from the awareness of symptom to diagnosis, number of hospitals visited by patients until CUP diagnosis, type of hospital at which the patient received a confirmed CUP diagnosis, availability of a second opinion consultation, and history of any cancer other than CUP.

\section{Sample size calculation}

We initially calculated a sample size of 60 cases in 2 groups based on an effect size (ES) of 0.5 , a of 0.05 , and power of 0.8 . From the first survey (J-HOPE 2016), we obtained 39 responses. We added the J-HOPE4 survey assuming that the impact of medical changes was minimal during the study period (2016-2018). 


\section{Statistical analyses}

For the background variables and item responses, descriptive statistics were calculated for the measured items in the CUP and common cancer groups, and between-group differences were examined using Student's t-test and one-way analysis of variance (ANOVA) for continuous variables and chi-squared test for categorical variables. Exploratory factor analysis was performed using the maximumlikelihood method. The repeated Promax rotation solution was used to confirm the identity of the underlying structure of the Burden scale.

The total and subscale scores were compared using multiple regression analysis to adjust for covariates between the groups, and Cohen's $d$ was used as ES. Multiple regression analysis was performed using the GDI and PHQ-9 scores as dependent variables and the Burden scores and background variables as independent variables for a subset of the CUP data. Furthermore, the determinants relevant to each subscale of Burden were analyzed for a subset of CUP data. Univariate analyses were performed with chi-squared analyses, one-way ANOVA, and t-tests, where appropriate. For multivariate analysis, multiple regression analysis was performed using items that had $\mathrm{P}<0.10$ in univariate analysis. Variable selection was performed using the variable reduction method.

A P value $<0.05$ was considered statistically significant. All analyses were performed using SPSS version 27.0 (IBM Japan Institute, Tokyo, Japan).

\section{Results}

The participating institutions were PCUs (258), home hospice services (14), and acute hospitals (14). The original dataset comprised a total of 27,591 respondents (Figure 1). For the families of CUP patients, 237 questionnaires were sent, 115 were returned (response rate, $48.5 \%$ ), and 97 were ultimately analyzed. For the families of non-CUP patients, 22,551 questionnaires were sent and 14,834 were returned (response rate, $65.8 \%$ ). Of these, 1,877 responses corresponded to the families of common cancer (lung, colon, and stomach) patients, and 717 were ultimately analyzed. Table 1 shows the characteristics of patients and their bereaved family members. Variables that were significantly different between the groups were patient gender $(P=0.006)$ and number of days elapsed since death $(P=$ 0.005). 
Table 1

Characteristics of participants $(\mathrm{N}=814)$

\begin{tabular}{|c|c|c|c|c|c|}
\hline & \multicolumn{2}{|l|}{ CUP a } & \multicolumn{3}{|c|}{ Common Cancers ${ }^{b}$} \\
\hline & $\mathrm{n} /$ mean & $\% / S D^{c}$ & $\mathrm{n} /$ mean & $\% / S D^{c}$ & $P$ value \\
\hline \multicolumn{6}{|l|}{ Patients } \\
\hline \multicolumn{6}{|l|}{ Sex } \\
\hline Male & 46 & 47.4 & 444 & 61.9 & $0.006^{d}$ \\
\hline Female & 51 & 52.6 & 273 & 38.1 & \\
\hline Age, years & 76.8 & 12.0 & 75.5 & 11.2 & $0.273^{e}$ \\
\hline$<65$ years & 16 & 0.2 & 116 & 16.2 & $0.068^{f}$ \\
\hline $65-75$ years & 21 & 0.2 & 201 & 28.0 & \\
\hline $75-85$ years & 26 & 26.8 & 234 & 32.6 & \\
\hline$\geq 85$ & 34 & 35.1 & 166 & 23.2 & \\
\hline \multicolumn{6}{|l|}{ Primary cancer site } \\
\hline Unknown & 97 & 100.0 & 0 & 0.0 & - \\
\hline Lung & 0 & 0.0 & 345 & 48.1 & \\
\hline Colon & 0 & 0.0 & 199 & 27.8 & \\
\hline Stomach & 0 & 0.0 & 173 & 24.1 & \\
\hline \multicolumn{6}{|c|}{ Chief complaint at the time of the first hospital visit } \\
\hline Pain & 40 & 23.7 & - & - & \\
\hline Swelling & 27 & 16.0 & - & - & \\
\hline Anorexia & 24 & 14.2 & - & - & \\
\hline Fatigue & 24 & 14.2 & - & - & \\
\hline Dyspnea & 13 & 7.7 & - & - & \\
\hline Fever & 11 & 6.5 & - & - & \\
\hline Other symptoms & 22 & 13.0 & - & - & \\
\hline None & 8 & 4.7 & - & - & \\
\hline \multicolumn{6}{|c|}{ Length from awareness of symptom to diagnosis } \\
\hline$<1$ month & 32 & 33.0 & - & - & \\
\hline
\end{tabular}

a Cancer of unknown primary site

b The three most common cancers in Japan (lung, colon, stomach) according to 2018 cancer statistics

${ }^{\mathrm{c}} \mathrm{SD}$, standard deviation

${ }^{d}$ Chi-squared analyses

e Student's t-tests

f One-way ANOVA

Several of the total percentage values shown above do not reach $100 \%$ due to missing data. 


\begin{tabular}{|c|c|c|c|c|c|}
\hline \multirow{2}{*}{$1-3$ months } & \multicolumn{2}{|l|}{ CUP a } & \multicolumn{3}{|c|}{ Common Cancers $^{b}$} \\
\hline & 35 & 36.1 & - & - & \\
\hline$\geq 3$ months & 19 & 19.6 & - & - & \\
\hline No symptom & 2 & 2.1 & - & - & \\
\hline \multicolumn{6}{|c|}{ Number of hospitals visited by patients until diagnosis } \\
\hline 1 & 15 & 15.5 & - & - & \\
\hline $2-5$ & 76 & 78.4 & - & - & \\
\hline$\geq 6$ & 2 & 2.1 & - & - & \\
\hline \multicolumn{6}{|c|}{ Hospital which received a confirmed diagnosis } \\
\hline Cancer center & 10 & 10.3 & - & - & \\
\hline University hospital & 28 & 28.9 & - & - & \\
\hline General hospital & 48 & 49.5 & - & - & \\
\hline Clinic & 3 & 3.1 & - & - & \\
\hline Other hospital & 3 & 3.1 & - & - & \\
\hline \multicolumn{6}{|c|}{ Second opinion consultation } \\
\hline Experienced. & 29 & 29.9 & - & - & \\
\hline Did not experience. & 64 & 66.0 & - & - & \\
\hline \multicolumn{6}{|c|}{ Number of primary departments } \\
\hline One & 52 & 53.6 & - & - & \\
\hline Two & 12 & 12.4 & - & - & \\
\hline Three & 7 & 7.2 & - & - & \\
\hline \multicolumn{6}{|c|}{ Previous experience with other cancers } \\
\hline Yes & 19 & 19.6 & - & - & \\
\hline No & 73 & 75.3 & - & - & \\
\hline \multicolumn{6}{|l|}{ Bereaved Families } \\
\hline \multicolumn{6}{|l|}{ Sex } \\
\hline Male & 26 & 26.8 & 217 & 30.3 & $0.732^{\mathrm{e}}$ \\
\hline Female & 64 & 66.0 & 491 & 68.5 & \\
\hline Age, years & 61.3 & 1.0 & 62.3 & 12.1 & $0.431^{f}$ \\
\hline \multicolumn{6}{|c|}{ a Cancer of unknown primary site } \\
\hline \multicolumn{6}{|c|}{$\mathrm{b}$ The three most common cancers in Japan (lung, colon, stomach) according to 2018 cancer statistics } \\
\hline \multicolumn{6}{|c|}{${ }^{\mathrm{c}} \mathrm{SD}$, standard deviation } \\
\hline \multicolumn{6}{|c|}{${ }^{d}$ Chi-squared analyses } \\
\hline \multicolumn{6}{|l|}{ e Student's t-tests } \\
\hline \multicolumn{6}{|l|}{ f One-way ANOVA } \\
\hline Several of the total & ch & & $\mathrm{gc}$ & & \\
\hline
\end{tabular}




\begin{tabular}{|c|c|c|c|c|c|}
\hline \multirow[b]{2}{*}{$55<$} & \multicolumn{2}{|l|}{ CUP a } & \multicolumn{3}{|c|}{ Common Cancers ${ }^{\text {b }}$} \\
\hline & 22 & 24.4 & 188 & 26.6 & $0.262^{f}$ \\
\hline $55-65<$ & 34 & 37.8 & 199 & 28.2 & \\
\hline $65-75<$ & 23 & 25.6 & 198 & 28.0 & \\
\hline$\geq 75$ & 11 & 12.2 & 121 & 17.1 & \\
\hline \multicolumn{6}{|c|}{ Relationship with the patient } \\
\hline Spouse & 34 & 35.1 & 291 & 40.6 & $0.366^{d}$ \\
\hline child & 39 & 40.2 & 296 & 41.3 & \\
\hline Son/Daughter in law & 9 & 9.3 & 40 & 5.6 & \\
\hline Parent & 0 & 0.0 & 19 & 2.6 & \\
\hline Sibling & 5 & 5.2 & 43 & & \\
\hline Other & 2 & 2.1 & 22 & 3.1 & \\
\hline \multicolumn{6}{|l|}{ Education } \\
\hline Junior high school & 3 & 3.1 & 75 & 10.5 & $0.075^{\mathrm{d}}$ \\
\hline High school & 36 & 37.1 & 321 & 44.8 & \\
\hline College & 21 & 21.6 & 149 & 20.8 & \\
\hline University & 28 & 28.8 & 139 & 19.4 & \\
\hline Graduate university & 1 & 1.0 & 6 & 0.8 & \\
\hline Other & 1 & 1.0 & 6 & 0.8 & \\
\hline \multicolumn{6}{|l|}{ Religion } \\
\hline Buddhism & 53 & 54.6 & 428 & 59.7 & $0.397^{d}$ \\
\hline Shintoism & 0 & 0.0 & 13 & 1.8 & \\
\hline Christianity & 2 & 2.1 & 14 & 2.0 & \\
\hline Other religion & 0 & 0.0 & 11 & 1.5 & \\
\hline No religion & 34 & 35.1 & 226 & 31.5 & \\
\hline \multicolumn{6}{|c|}{ Period from date of patient death to date of survey return } \\
\hline Mean & 318.1 & 133.8 & 278.2 & 130.3 & $0.005^{f}$ \\
\hline$>6$ months & 8 & 8.2 & 162 & 22.6 & $0.002^{f}$ \\
\hline
\end{tabular}

a Cancer of unknown primary site

b The three most common cancers in Japan (lung, colon, stomach) according to 2018 cancer statistics

${ }^{\mathrm{c}} \mathrm{SD}$, standard deviation

${ }^{d}$ Chi-squared analyses

e Student's t-tests

f One-way ANOVA

Several of the total percentage values shown above do not reach $100 \%$ due to missing data. 


\begin{tabular}{|c|c|c|c|c|}
\hline \multirow[b]{2}{*}{ 6-12 months } & \multicolumn{2}{|c|}{ CUP a } & \multicolumn{2}{|c|}{ Common Cancers $^{b}$} \\
\hline & 63 & 64.9 & 450 & 62.8 \\
\hline 13-18 months & 19 & 19.6 & 68 & 9.5 \\
\hline 19-24 months & 5 & 5.2 & 26 & 3.6 \\
\hline$\geq 25$ months & 2 & 2.1 & 11 & 1.5 \\
\hline \multicolumn{5}{|c|}{${ }^{a}$ Cancer of unknown primary site } \\
\hline \multicolumn{5}{|c|}{ b The three most common cancers in Japan (lung, colon, stomach) according to 2018 cancer statistics } \\
\hline \multicolumn{5}{|c|}{ c SD, standard deviation } \\
\hline \multicolumn{5}{|c|}{${ }^{d}$ Chi-squared analyses } \\
\hline \multicolumn{5}{|l|}{ e Student's t-tests } \\
\hline \multicolumn{5}{|l|}{${ }^{f}$ One-way ANOVA } \\
\hline
\end{tabular}

\section{Frequency distribution and factor analysis of the Burden scale}

Table 2 shows the percentage of family members who answered" sometimes" or "often" to each Burden item. Among the families of CUP patients, the questions that received a "sometimes" or "often" response $50 \%$ of the time or more were patient exhaustion due to the large number of evaluations (73.9\%), anxiety associated with the prolonged diagnosis period $(70.2 \%)$, and uncertainty about the future progression of the cancer (56.3\%). 
Table 2

Frequency distribution and factor analysis of Burden among family members of CUP patients and those of common cancer patients

\begin{tabular}{|c|c|c|c|c|c|c|c|c|c|c|c|c|}
\hline \multirow{3}{*}{$\begin{array}{l}\text { Item and } \\
\text { Factor }\end{array}$} & \multicolumn{3}{|c|}{ Factor loading } & \multirow[t]{3}{*}{ h2 } & \multicolumn{4}{|l|}{ CUP $^{a}$} & \multicolumn{4}{|c|}{ Common cancers ${ }^{b}$} \\
\hline & \multirow[t]{2}{*}{ I } & \multirow[t]{2}{*}{ II } & \multirow[t]{2}{*}{ III } & & \multirow{2}{*}{$\begin{array}{l}\text { Mean } \\
\text { c }\end{array}$} & \multirow[t]{2}{*}{$S D^{d}$} & \multicolumn{2}{|c|}{$\%(n)$ of subjects } & \multirow{2}{*}{$\begin{array}{l}\text { Mean } \\
\text { c }\end{array}$} & \multirow[t]{2}{*}{$S D^{d}$} & \multicolumn{2}{|c|}{$\%(n)$ of subjects } \\
\hline & & & & & & & Sometimes & Often & & & Sometimes & Often \\
\hline \multicolumn{13}{|l|}{$\begin{array}{l}\text { F1: Difficulty in } \\
\text { accessing } \\
\text { specialist } \\
\text { doctors }(a= \\
0.844)\end{array}$} \\
\hline $\begin{array}{l}\text { Q5: I thought } \\
\text { that the doctor } \\
\text { might abandon } \\
\text { us. }\end{array}$ & 0.84 & 0.04 & -0.07 & 0.67 & 1.97 & 0.96 & $18.3(17)$ & $\begin{array}{l}8.6 \\
(8)\end{array}$ & 1.79 & 0.86 & 13.9 (99) & $\begin{array}{l}5.0 \\
(36)\end{array}$ \\
\hline $\begin{array}{l}\text { Q4: It was hard } \\
\text { for me to find } \\
\text { specialists with } \\
\text { the skills } \\
\text { needed to treat } \\
\text { the patient's } \\
\text { disease. }\end{array}$ & 0.76 & 0.15 & -0.05 & 0.71 & 2.31 & 1.09 & $21.3(20)$ & $\begin{array}{l}19.1 \\
(18)\end{array}$ & 1.88 & 0.84 & $17.6(125)$ & $\begin{array}{l}4.2 \\
(30)\end{array}$ \\
\hline $\begin{array}{l}\text { Q3: I thought } \\
\text { that the } \\
\text { doctor's } \\
\text { recommended } \\
\text { course of } \\
\text { medical care } \\
\text { might be } \\
\text { wrong. }\end{array}$ & 0.61 & -0.13 & 0.35 & 0.62 & 2.08 & 0.88 & $12.9(12)$ & $\begin{array}{l}9.7 \\
(9)\end{array}$ & 1.95 & 0.85 & 19.4 (138) & $\begin{array}{l}4.8 \\
(34)\end{array}$ \\
\hline
\end{tabular}

\section{F2: Uncertainty} due to lack of

information about the disease $(a=$ 0.821)

Q8: I felt it was difficult for me to obtain information regarding the patient's disease from

books, the internet, etc.

\begin{tabular}{|c|c|c|c|c|c|c|c|c|c|c|c|c|}
\hline $\begin{array}{l}\text { Q7: I } \\
\text { experienced } \\
\text { uncertainty due } \\
\text { to the } \\
\text { unpredictability } \\
\text { of the cancer's } \\
\text { future } \\
\text { progression. }\end{array}$ & 0.15 & 0.59 & 0.15 & 0.69 & 2.62 & 1.02 & $34.0(32)$ & $\begin{array}{l}22.3 \\
(21)\end{array}$ & 2.16 & 0.91 & $28.2(201)$ & $\begin{array}{l}7.6 \\
(54)\end{array}$ \\
\hline $\begin{array}{l}\text { Q6: I thought } \\
\text { that other } \\
\text { people around } \\
\text { us would not } \\
\text { understand the } \\
\text { unique } \\
\text { characteristics } \\
\text { of the patient's } \\
\text { cancer. }\end{array}$ & 0.34 & 0.49 & -0.02 & 0.59 & 2.28 & 1.00 & $25.5(24)$ & $\begin{array}{l}13.8 \\
(13)\end{array}$ & 1.85 & 0.80 & 14.5 (102) & $\begin{array}{l}3.7 \\
(26)\end{array}$ \\
\hline
\end{tabular}

F3:

Psychological

burden

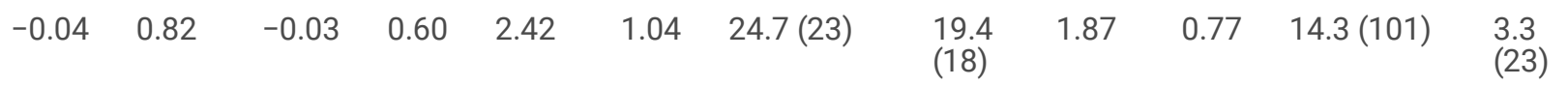




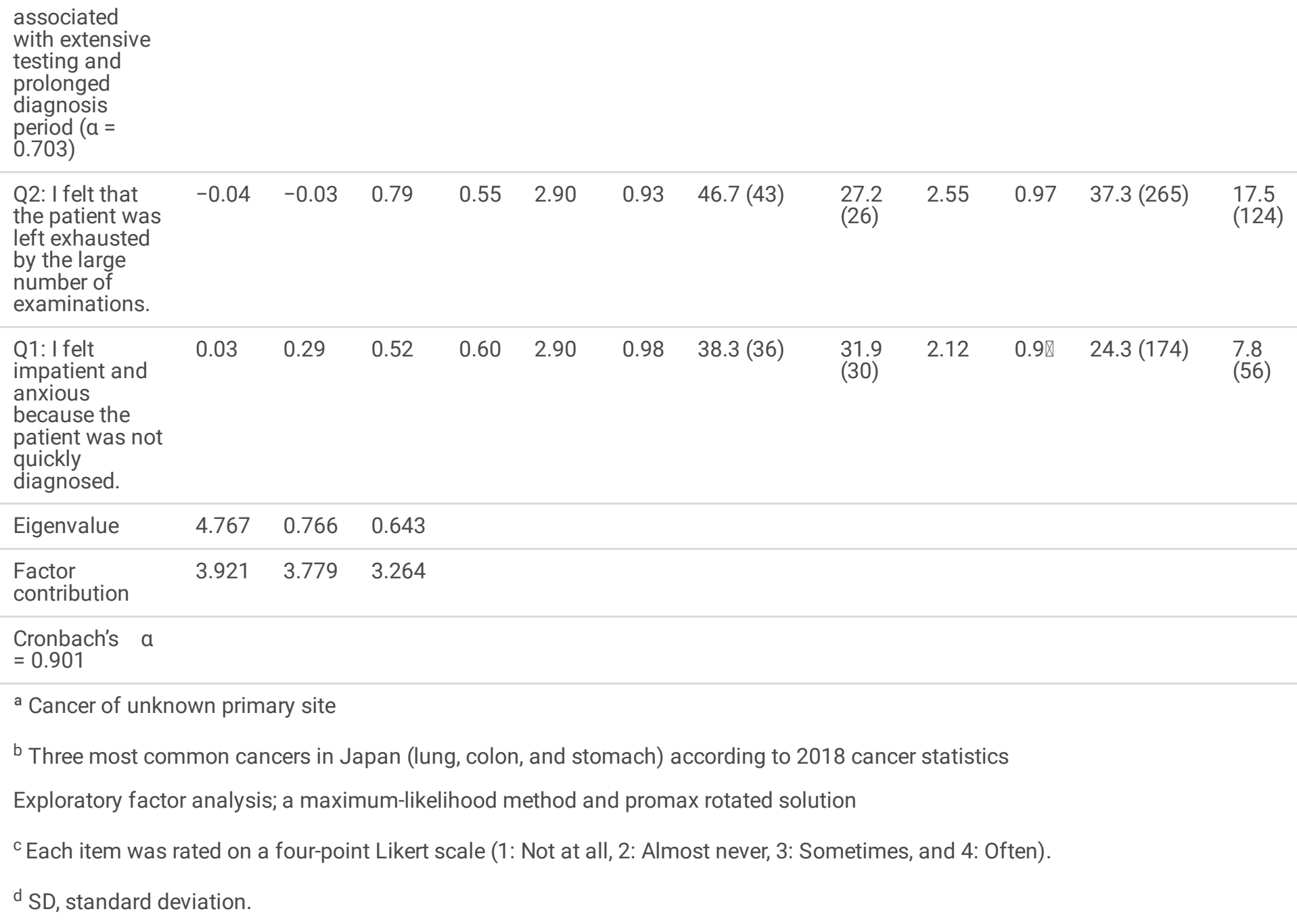

Exploratory factor analysis identified three underlying structures of the Burden scale (Table 2): 1) Factor-1: "Difficulty in accessing specialist doctors" (specialist subscale, $a=0.844$ ), comprising three items; 2) Factor-2: "Uncertainty due to lack of information about the disease" (uncertainty subscale, $a=0.821$ ), consisting three items; and 3 ) Factor-3: "Psychological burden associated with extensive testing and prolonged diagnosis period" (prolonged diagnosis subscale, $a=0.703$ ), consisting two items. Cronbach's alpha across the eight items was 0.901 .

\section{Comparison of Burden between family members of CUP patients and those of common cancer patients}

Table 3 shows the difference in the mean family-perceived Burden score associated with cancer testing and diagnosis between the groups, after adjusting for covariates, i.e., patient age, gender, and relationship to the patient. The scores for all three factors of Burden were significantly higher for the CUP group than the common cancers group: specialist subscale $(E S=0.30, A d j P=0.010)$, uncertainty subscale $(E S=0.66, \operatorname{AdjP}<0.0001)$, and prolonged diagnosis subscale $(E S=0.69, \operatorname{AdjP}<0.0001)$. 
Table 3

Comparison of Burden between family members of CUP patients and those of common cancer patients

\begin{tabular}{|c|c|c|c|c|c|c|}
\hline & \multicolumn{2}{|l|}{ CUP a } & \multicolumn{4}{|c|}{ Common cancers ${ }^{b}$} \\
\hline & Mean ${ }^{c}$ & $S D^{d}$ & Mean ${ }^{c}$ & $S^{d}$ & Effect size $e^{e}$ & Adj $P$ value ${ }^{f}$ \\
\hline Total score & 2.42 & 0.77 & 2.01 & 0.66 & 0.60 & $<0.0001$ \\
\hline F1: Specialist subscale ${ }^{g}$ & 2.10 & 0.84 & 1.87 & 0.74 & 0.30 & 0.010 \\
\hline F2: Uncertainty subscale ${ }^{h}$ & 2.43 & 0.89 & 1.96 & 0.70 & 0.66 & $<0.0001$ \\
\hline F3: Prolonged diagnosis subscale ${ }^{i}$ & 2.90 & 0.85 & 2.34 & 0.82 & 0.69 & $<0.0001$ \\
\hline \multicolumn{6}{|c|}{ a Cancer of unknown primary site } & b The three most common cancers in Japan (lung, colon, stomach) according to 2018 cancer statistics \\
\hline \multicolumn{7}{|c|}{ c Each item was rated on a four-point Likert scale (1: Not at all, 2: Almost never, 3: Sometimes, and 4: Often). } \\
\hline \multicolumn{7}{|l|}{${ }^{\mathrm{d}} \mathrm{SD}$, standard deviation } \\
\hline \multicolumn{7}{|l|}{ e Effect size: Cohen's d } \\
\hline \multirow{2}{*}{\multicolumn{7}{|c|}{${ }^{f}$ Adjusted P value for Characteristics (Patient: age, sex; bereaved family members: relationships), A multiple regression analysis }} \\
\hline & & & & & & \\
\hline \multicolumn{7}{|c|}{${ }^{\mathrm{h}} \mathrm{F} 2$ : Uncertainty due to lack of information about the disease } \\
\hline ' F3: Psychological burden asso & SI & ga & onge & sis & & \\
\hline
\end{tabular}

\section{Association of patients' QOL at end-of-life and bereaved family member's depression with Burden associated with cancer testing and diagnosis (CUP data only)}

Table 4 shows the correlation of GDI or PHQ-9 score with the three factors of Burden, after adjusting for patient age, gender, and relationship to the patient (only in the case of PHQ-9, the period after the patient's death was added). There was a significant association of all three factors of Burden with GDI and PHQ-9. Strongly associated factors included uncertainty subscale with GDI (Std $\beta=-0.41, \operatorname{Adj} P<0.0001)$, specialist subscale with $P H Q(S t d \beta=0.29$, AdjP $=0.012)$, and prolonged diagnosis subscale with $P H Q$ (Std $\beta$ $=0.29, \operatorname{AdjP}=0.011$. 
Table 4

Association of patients' QOL at end-of-life and bereaved family member's depression with Burden associated with cancer testing and diagnosis (CUP data only)

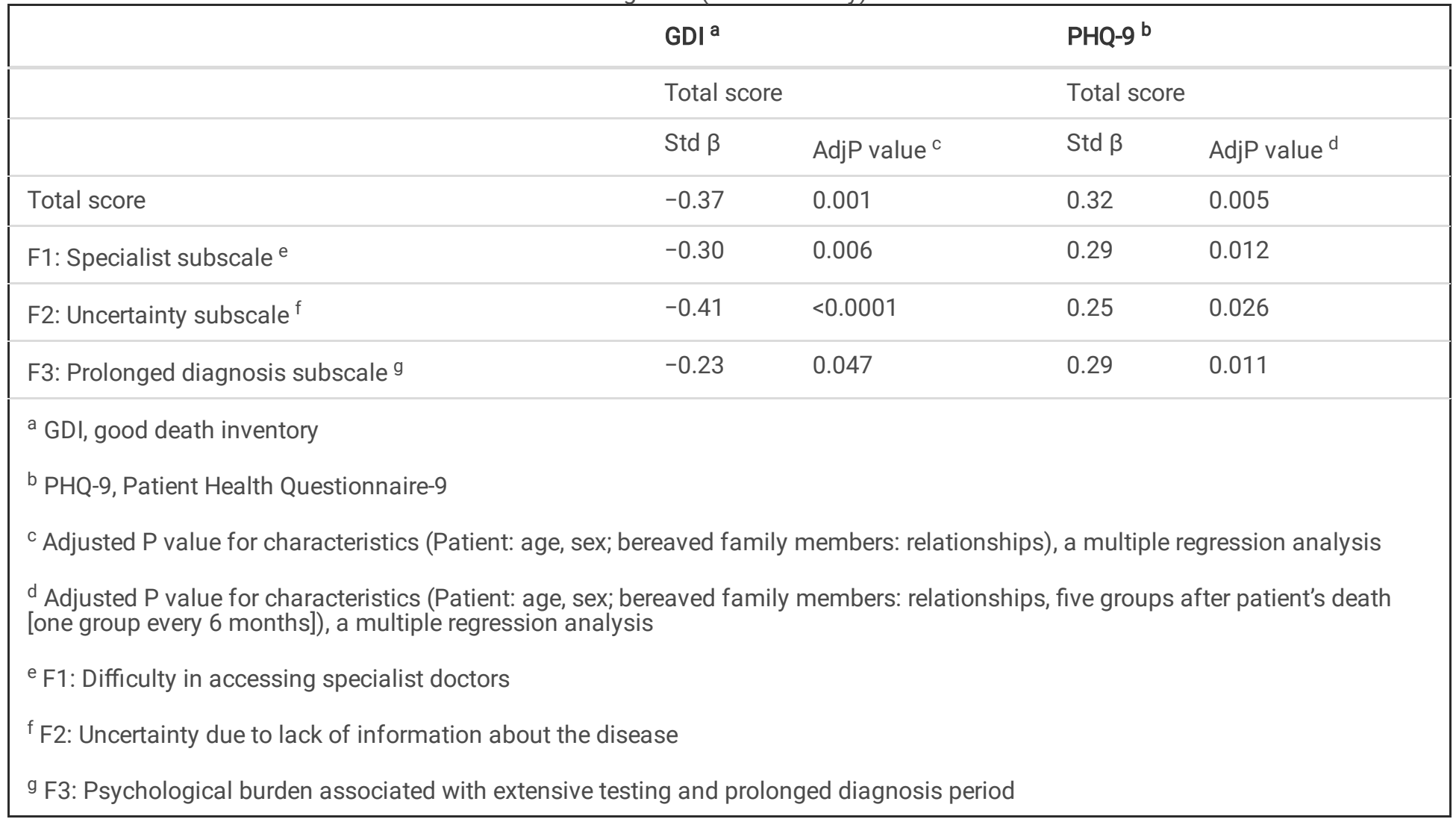

\section{Factors related to family-perceived Burden associated with cancer testing and diagnosis (CUP data only)}

Factors associated with Burden are summarized in Table 5. Multiple regression analysis identified that the independent factors for total and subscale scores for Burden included relationship to the patient (spouse had higher Burden), duration of diagnosis ( $\geq 1$ month was associated with a higher Burden), and second opinion consultation (families who reported a second opinion consultation had a higher Burden). 
Table 5

Factors related to family-perceived burden associated with cancer testing and diagnosis (CUP data only)

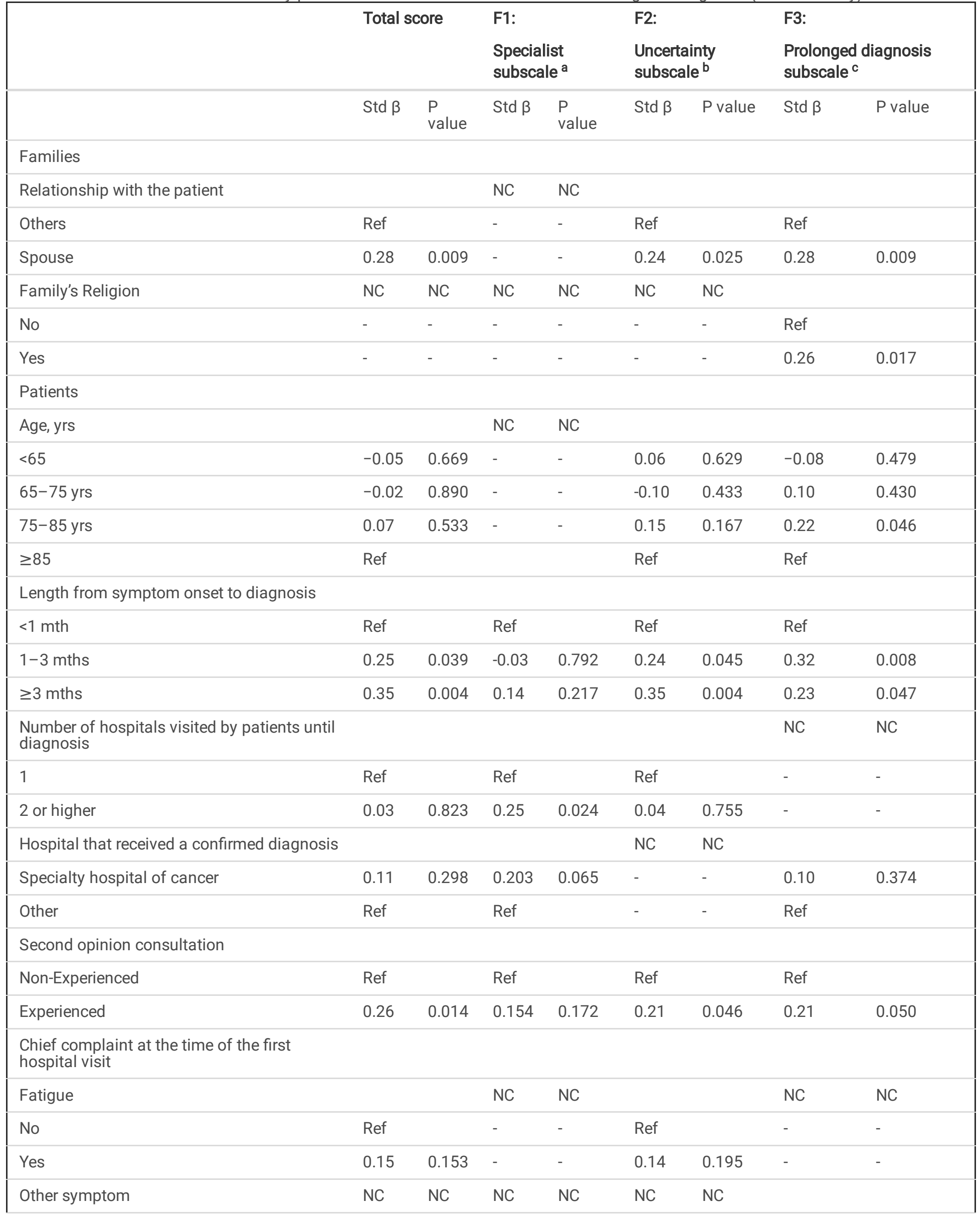




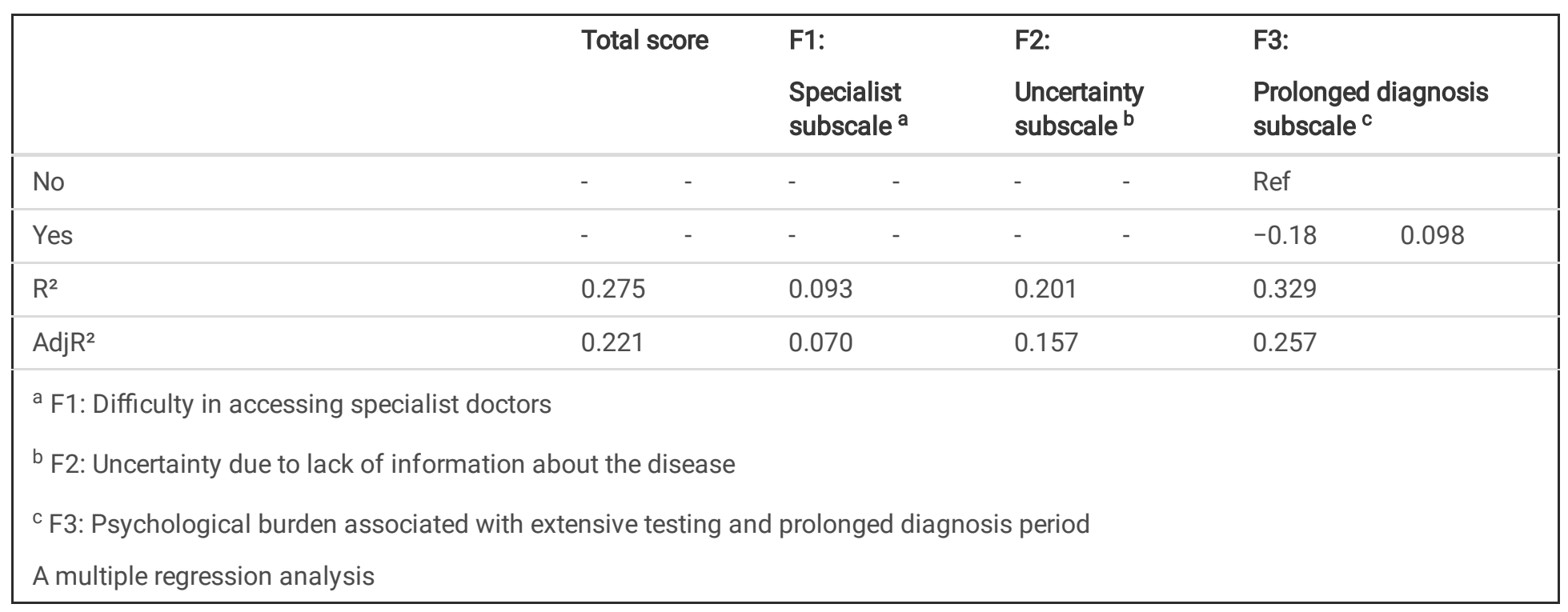

\section{Discussion}

To the best of our knowledge, this is the first study comparing family experiences between CUP and common cancer patients. Familyperceived burden associated with cancer examination and diagnosis was significantly higher in the families of CUP patients than in those of common cancer patients, and their perceived burden was significantly associated with patients' QOL at end-of-life and family depression. In addition, a diagnosis that required $\geq 1$ month and receiving a second opinion consultation were significantly associated with burden.

Family-perceived burden comprises three components, namely specialist access, uncertainty, and prolonged diagnosis. All three of these subscales were significantly higher in the families of CUP patients than in those of common cancer patients. This difference may be because CUP usually presents with atypical symptoms; thus, physicians are often unfamiliar with diagnosing CUP [6]. This is analogous to rare cancers requiring a longer time for diagnosis than common cancers $[27,28]$. In particular, the uncertainty and prolonged diagnosis subscales showed significant and large differences between CUP and common cancers. These findings confirm the results of previous qualitative studies [9-11], suggesting that CUP patients undergo prolonged examinations with high uncertainty. In CUP, a comprehensive strategy to establish access to specialists, obtain an early diagnosis, and reduce the uncertainty experienced by patients and their families is urgently required.

Another important finding is that a higher Burden score was significantly correlated with lower patient QOL at end-of-life (GDI) and higher depression among bereaved family members. CUP patients are often symptomatic before the definitive diagnosis [29], are typically diagnosed during an unplanned hospital admission, and have very poor survival [30]. Owing to these characteristics, the family-perceived burden during the diagnostic process affects not only the CUP patients at the end-of-life but also their bereaved families. Establishing a comprehensive care strategy for CUP patients and their families may improve patients' QOL at end-of-life and post-bereavement depression.

A notable result of our analysis is the identification of a reasonable diagnosis period from the perspective of a healthcare recipient as being "within 1 month"; this is in agreement with the guidelines [31] for the appropriate diagnosis of CUP, which is typically associated with a prolonged diagnostic period [32-34]. Clarifying specific periods in diagnosing CUP may be helpful for clinicians during the initial diagnostic phase.

Of note, the difference in the specialist subscale was relatively lower than that in the other two subscales. This may be due to the presence of a national health insurance system covered by the government that is available to the Japanese population [35]. In the Japanese healthcare system, all patients can freely choose medical institutions and receive medical treatment anytime within the upper limits of expenses ( 1000 USD per month); therefore, it is rare for anyone to have no access to healthcare at all [35, 36]. Additionally, most Japanese, particularly the elderly, prefer the traditional culture of "leave it to the doctor" [37]. Although there are indications of inequalities in access to services in CUP [32-34], it is possible that this cultural background in Japan is reflected in our results.

\section{Strengths and limitations}


This study has multiple strengths, including the use of a nationwide sample, use of common cancer patients as a reference group to make comparisons, and use of validated measures of good death (GDI). However, this study also has several limitations. First, the response rate was moderate (48.5\%) and we could not compare the backgrounds between responding and nonresponding families; thus, there may be some selection bias. Second, although the responses of the 97 bereaved families of CUP patients were from nationwide surveys, they are not fully representative because the patients were mainly recruited from a convenient sample of specialized palliative care services. Third, recall bias may have occurred owing to retrospective assessment by bereaved family members. Fourth, although the outcome measures had good psychometric properties, including factor validity and internal consistency, reliability and validity was not formally tested.

\section{Conclusions}

Family-perceived burden associated with cancer testing and diagnosis was higher among the families of CUP patients than those with common cancers, and the higher burden was correlated with lower patient QOL at end-of-life and higher depression among bereaved family members. Burden comprised three factors: specialist access, uncertainty, and prolonged diagnosis; it was significantly associated with the relationship to the patient (spouse), prolonged diagnosis (>1 month), and second opinion consultation. CUP patients and their families should be cared for from the initial stages to establish access to specialists, obtain an early diagnosis, and reduce uncertainty.

\section{Declarations}

\section{Funding}

This study was funded by the Japan Hospice Palliative Care Foundation (No grant number).

\section{Competing Interests}

The authors have no relevant financial or non-financial interests to disclose.

\section{Author Contributions}

Conceptualization: Kyoko Ishida, Shoko Ando, Hirokazu Komatsu, Megumi Uchida, Tatsuya Morita, Tatsuo Akechi, Mitsunori Miyashita; Formal analysis: Kazuki Sato, Kyoko Ishida, Shoko Ando; Investigation and data management: Kento Masukawa, Naoko Igarashi, Mitsunori Miyashita; Writing - original draft preparation: Kyoko Ishida; Writing - review and editing: Tatsuya Morita, Tatsuo Akechi, Shoko Ando, Kazuki Sato, Kyoko Ishida, Hirokazu Komatsu, Megumi Uchida, Mitsunori Miyashita; Funding acquisition: Mitsunori Miyashita; Resources: Mitsunori Miyashita, Yoshiyuki Kizawa, Satoru Tsuneto, Yasuo Shima; Supervision: Shoko Ando.

All authors commented on previous versions of the manuscript. All authors read and approved the final manuscript.

\section{Ethics Approval}

This study was conducted with the approval of the ethics committee of Tohoku University School of Medicine (No: 2016-1-015, 2017-2236-1), Nagoya University School of Medicine (No:17-167), and the ethics committees of all participating institutions. All study procedures were conducted according to the principles of World Medical Association Declaration of Helsinki.

\section{Consent to participate}

Informed consent was obtained from all family members included in the study.

\section{Consent to publish}

Informed consent was obtained from all family members for the possible publication of the results.

\section{Data Availability Statement}

The data supporting the study results are available from the corresponding author upon reasonable request.

\section{Acknowledgments}


We thank the Hospice Palliative Care Japan (HPCJ) and participating institutions for their cooperation.

\section{References}

1. Pavlidis N, Pentheroudakis G (2012) Cancer of unknown primary site. Lancet 379:1428-1435.

2. Fizazi K, Greco FA, Pavlidis N et al (2015) Cancers of unknown primary site: ESMO Clinical Practice Guidelines for diagnosis, treatment and follow-up. Ann Oncol 26:v133-v138.

3. Losa F, Soler G, Casado A et al (2018) SEOM clinical guideline on unknown primary cancer (2017). Clin Transl Oncol 20:89-96.

4. Alshareeda AT, Al-Sowayan BS, Alkharji RR, Aldosari SM, Al Subayyil AM, Alghuwainem A (2020) A cancer of unknown primary site: real entity or misdiagnosed disease? J Cancer 11:3919-3931.

5. Rassy E, Assi T, Pavlidis N (2020) Exploring the biological hallmarks of cancer of unknown primary: where do we stand today? $\mathrm{Br} \mathrm{J}$ Cancer 122:1124-1132.

6. Mendonca SC, Abel GA, Lyratzopoulos G (2016) Pre-referral GP consultations in patients subsequently diagnosed with rarer cancers: A study of patient-reported data. Br J Gen Pract 66:e171-e181.

7. Rassy E, Parent P, Lefort F, Boussios S, Baciarello G, Pavlidis N (2020) New rising entities in cancer of unknown primary: is there a real therapeutic benefit? Crit Rev Oncol Hematol 147:102882.

8. Rassy E, Pavlidis N (2019) The currently declining incidence of cancer of unknown primary. Cancer Epidemiol 61:139-141.

9. Boyland L, Davis C (2008) Patients' experiences of carcinoma of unknown primary site: dealing with uncertainty. Palliat Med 22:177-183.

10. Richardson A, Wagland R, Foster R et al (2015) Uncertainty and anxiety in the cancer of unknown primary patient journey: a multiperspective qualitative study. BMJ Support Palliat Care 5:366-372.

11. Ishida K, Ando S, Komatsu H, Kinoshita S, Mori Y, Akechi T (2016) Psychological burden on patients with cancer of unknown primary: from onset of symptoms to initial treatment. Jpn J Clin Oncol 46:652-660.

12. Wagland R, Bracher M, Drosdowsky A et al (2017) Differences in experiences of care between patients diagnosed with metastatic cancer of known and unknown primaries: mixed-method findings from the 2013 cancer patient experience survey in England. BMJ Open 7:e017881.

13. Northouse L, Williams AL, Given B, McCorkle R, Netter FH (2012) Psychosocial care for family caregivers of patients with cancer. J Clin Oncol 30:1227-1234.

14. Hagedoorn M, Sanderman R, Bolks HN, Tuinstra J, Coyne JC (2008) Distress in couples coping with cancer: A meta-analysis and critical review of role and gender effects. Psychol Bull 134:1-30.

15. Braun M, Mikulincer M, Rydall A, Walsh A, Rodin G (2007) Hidden morbidity in cancer: spouse caregivers. J Clin Oncol 25:48294834.

16. Nielsen MK, Neergaard MA, Jensen AB, Vedsted P, Bro F, Guldin MB (2017) Predictors of complicated grief and depression in bereaved caregivers: a nationwide prospective cohort study. J Pain Symptom Manage 53:540-550.

17. Götze H, Brähler E, Gansera L, Schnabel A, Gottschalk-Fleischer A, Köhler N (2018) Anxiety, depression and quality of life in family caregivers of palliative cancer patients during home care and after the patient's death. Eur J Cancer Care (Engl) 27:e12606.

18. Aoyama M, Morita T, Kizawa Y, Tsuneto S, Shima Y, Miyashita M (2017) The Japan HOspice and palliative care evaluation Study 3: study design, characteristics of participants and participating institutions, and response rates. Am J Hosp Palliat Care 34:654-664.

19. Masukawa K, Aoyama M, Morita T et al (2018) The Japan hospice and palliative evaluation study 4: A cross-sectional questionnaire survey. BMC Palliat Care 17:66.

20. Mishel MH (1988) Uncertainty in illness. Image J Nurs Sch 20:225-232.

21. Nogawa M (2004) Study on the reliability and validity of the Japanese-language version of Mishel uncertainty in illness scalecommunity form (in Japanese). J Jpn Acad Nurs Sci 24:39-48. https://www.jstage.jst.go.jp/article/jans1981/24/3/24_39/_pdf.

22. Miyashita M, Morita T, Sato K, Hirai K, Shima Y, Uchitomi Y (2008) Good death inventory: A measure for evaluating good death from the bereaved family Member's perspective. J Pain Symptom Manage 35:486-498.

23. Kroenke K, Spitzer RL, Williams JBW (2001) The PHQ-9 validity of a brief depression severity measure. J Gen Intern Med 16:606613. 
24. Löwe B, Kroenke K, Herzog W, Gräfe K (2004) Measuring depression outcome with a brief self-report instrument: sensitivity to change of the Patient Health Questionnaire (PHQ-9). J Affect Disord 81:61-66.

25. Spitzer RL, Kroenke K, Williams JBW (1999) Validation and utility of a self-report version of PRIME-MD: the PHQ primary care study. Primary Care Evaluation of Mental Disorders. Patient Health Questionnaire. JAMA 282:1737-1744.

26. Wright AA, Keating NL, Balboni TA, Matulonis UA, Block SD, Prigerson HG (2010) Place of death: correlations with quality of life of patients with cancer and predictors of bereaved caregivers' mental health. J Clin Oncol 28:4457-4464.

27. Lyratzopoulos G, Abel GA, McPhail S, Neal RD, Rubin GP (2013) Measures of promptness of cancer diagnosis in primary care: secondary analysis of national audit data on patients with 18 common and rarer cancers. Br J Cancer 108:686-690.

28. Kawai A, Higashi T, Shibata T et al (2020) Rare cancers in Japan: definition, clinical features and future perspectives. Jpn J Clin Oncol 50:970-975.

29. Vajdic CM, Schaffer AL, Dobbins TA, Ward RL, Er CC, Pearson SA (2015) Health service utilisation and investigations before diagnosis of cancer of unknown primary (CUP): a population-based nested case-control study in Australian government Department of Veterans' Affairs clients. Cancer Epidemiol 39:585-592.

30. Jones W, Allardice G, Scott I, Oien K, Brewster D, Morrison DS (2017) Cancers of unknown primary diagnosed during hospitalization: a population-based study. BMC Cancer 17:85.

31. NICE. Metastatic malignant disease of unknown primary origin. Rev Lit Arts Am. 2010 (July).

32. Crawford SM, Skinner J, Coombes E, Jones AP (2017) Cancer of unknown primary: A cancer registry study of factors affecting access to diagnosis. Clin Oncol (R Coll Radiol) 29:e39-e46.

33. Matsubara N, Mukai H, Nagai S, Itoh K (2010) Review of primary unknown cancer: cases referred to the National Cancer Center Hospital East. Int J Clin Oncol 15:578-582.

34. Creak A (2020) Prospective cohort of referrals to a cancer of unknown primary clinic, including direct access from primary care. Clin Oncol (R Coll Radiol) 32:e87-e92.

35. Universal P, Coverage H, Coverage U (2015) Study of global health strategy based on-international trends-promoting universal health coverage globally and ensuring the sustainability of Japan's universal coverage of health insurance system: problems and proposals. JMAJ 58:78-101.

36. Shibuya K, Ikegami N, Nishi A et al (2011) Future of Japan's system of good health at low cost with equity: beyond universal coverage. Lancet 378:1265-1273.

37. Akechi T, Miyashita M, Morita T et al (2012) Good death in elderly adults with cancer in Japan based on perspectives of the general population. J Am Geriatr Soc 60:271-276.

\section{Figures}




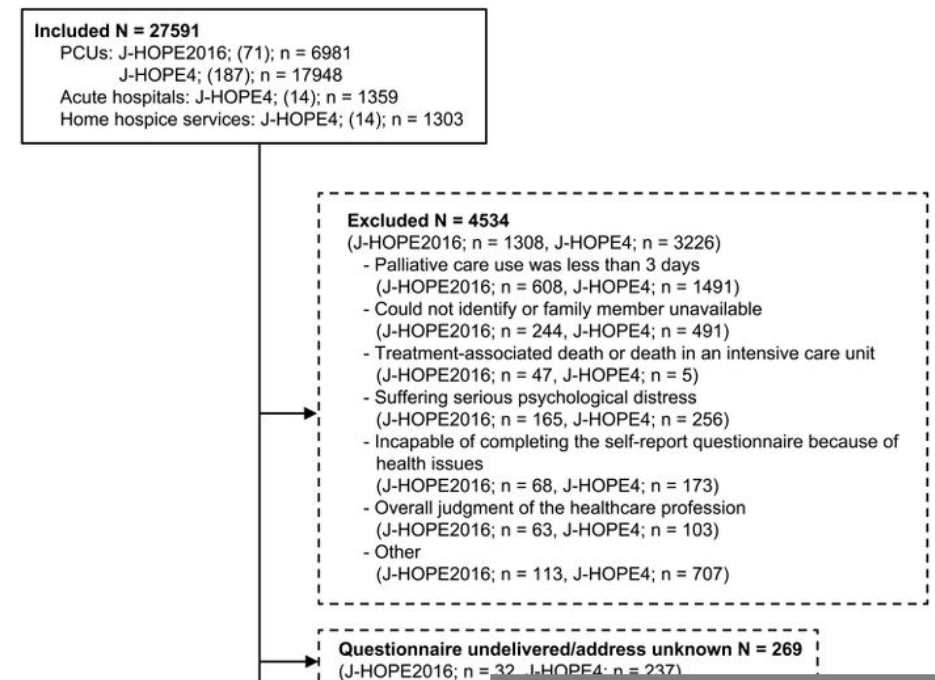

\section{Figure 1}

Legend not included with this version. 